\title{
Peripheral nerve blocks and postoperative physical therapy: a single-institution survey of physical therapists' preferences and opinions*
}

\author{
Robert L. McClain ${ }^{1}$, Steven B. Porter ${ }^{1}$, Scott M. Arnold ${ }^{2}$, Christopher B. Robards ${ }^{1}$
}

${ }^{1}$ Department of Anesthesiology and Perioperative Medicine, Mayo Clinic, Jacksonville, Florida, USA

${ }^{2}$ Department of Physical Medicine \& Rehabilitation, Mayo Clinic, Jacksonville, Florida, USA

\begin{abstract}
Background and Aims: Our aim was to ascertain the opinions and preferences of physical therapists with regard to use of peripheral nerve blocks and their impact on the recovery of patients undergoing total joint replacement.

Methods: We conducted an anonymous 24-question survey of 20 full-time inpatient physical therapists at a single tertiary care medical center.

Results: One respondent indicated they never work with patients who have undergone total joint replacement surgery. Nineteen questionnaires were included in the final analysis. Questions omitted by respondents or with write-in answers were not included in the analysis. A majority of respondents (15 [78.9\%]) agreed nerve blocks somewhat to greatly improve a patient's pain after total joint replacement surgery. Most respondents answered that nerve blocks somewhat to greatly impede a patient's ability to participate in physical therapy $(14[73.6 \%])$ and make therapy somewhat to very difficult for them as physical therapists $(16[84.2 \%])$. When asked about specific surgeries, $(17 / 18[94.4 \%])$ and $(14 / 18$ [77.8\%]) of respondents would prefer that their patients receive periarticular infiltration or no block at all after total knee arthroplasty or total hip arthroplasty, respectively. All respondents (19 [100\%]) answered that they thought lower extremity nerve blocks increased a patient's risk of falling after surgery.

Conclusions: According to the physical therapists we surveyed, nerve blocks impede patient recovery and increase the risk of falls, despite their positive impact on pain control. When considering surgery for themselves, therapists indicated they would not want a nerve block.

Keywords: peripheral nerve blocks; physical therapy; postoperative analgesia; postoperative recovery; total joint replacement
\end{abstract}

\section{Introduction}

Early physical therapy (PT) is important to improve functional recovery following total joint replacement (TJR) surgery [1-8]. Adequate analgesia is essential for patients to participate in PT after TJR. Regional

Address for correspondence: Steven Porter, MD Department of Anesthesiology and Perioperative Medicine, Mayo Clinic 4500 San Pablo Road

Jacksonville, FL 32224, USA

E-mail: porter.steven@mayo.edu anesthesia in the form of a peripheral nerve block (PNB) can provide substantial pain control after TJR while also limiting the use of opioid medications [9]. However, PNB has the potential to produce muscle weakness, theoretically hindering PT after surgery [10]. These perceived shortcomings of regional anesthesia have led some providers to prefer periarticular infiltration of local anesthetic to improve analgesia while avoiding potential muscle weakness associated with PNB [11]. While there is no standard analgesic method for TJR patients, some providers have developed preferences for one method over another. Physical therapists spend a great deal of 1-on-1 time interacting with

* Presented at the American Society of Regional Anesthesia 2016 Spring Meeting, New Orleans, Louisiana, USA 
TJR patients postoperatively. Also, PT metrics are part of many protocols for enhanced recovery after surgery. To this end, we conducted a survey of our institution's physical therapists to ascertain their opinions on pain control modalities based on their experience working with patients who have undergone TJR. In addition, we asked the physical therapists what form of regional anesthesia they would prefer if they were to undergo a TJR surgery.

The perioperative plan for patients undergoing total knee arthroplasty (TKA) and total hip arthroplasty (THA) at our institution has changed over time. Prior to 2012, patients undergoing TKA, barring contraindications, received a spinal anesthetic with continuous femoral and sciatic (intermittent catheter bolus dosing) blocks for postoperative analgesia. In 2012, anesthesiologists began combining spinal anesthetics with continuous adductor canal and sciatic (intermittent catheter bolus dosing) blocks. As of 2014, patients undergoing TKA receive spinal anesthetics and periarticular infiltration by the surgeon for postoperative analgesia. Patients who underwent THA received spinal anesthetics combined with continuous lumbar plexus block with or without a single injection sciatic nerve block for postoperative analgesia. Total shoulder arthroplasty patients received general anesthetics combined with continuous interscalene brachial plexus block for postoperative analgesia.

\section{Methods}

This study was deemed exempt by the Mayo Clinic Institutional Review Board. An anonymous, multiplechoice, Likert-type scaled questionnaire (Appendix 1) was distributed to every full-time inpatient physical therapist at Mayo Clinic in Jacksonville, Florida. Once completed, the questionnaires were collected and answers tabulated.

\section{Statistical Analysis}

The nonparametric ordinal-type data set was analyzed by identifying associations between each question.
Likert-type scaled survey questions were explored by constructed exact binomial 95\% confidence intervals, a validated method for analyzing this type of data [12]. All analyses were performed using SAS version 9.3 software (Cary, NC, USA: SAS Institute Inc.).

\section{Results}

Twenty full-time inpatient physical therapists at our institution received questionnaires, and all 20 questionnaires were returned (100\% response rate). One respondent indicated they never work with patients who have undergone TJR surgery, so 19 questionnaires were included in the final analysis. Questions that were omitted by respondents or had a write in answer were also not included in the analysis.

While most respondents (15 [78.9\%]) agreed that PNB somewhat to greatly improve a patient's pain after TJR surgery, most also answered that nerve blocks somewhat to greatly impede a patient's ability to participate in PT and make PT somewhat to very difficult for the physical therapist (14 [73.6\%] and 16 [84.2\%], respectively). When asked about specific surgeries, only $1 / 18(5.6 \%)$ respondents answered that they would prefer their patients receive a nerve block after TKA, while only $4 / 18$ (22.2\%) felt the same about patients after THA. Responses were nearly identical when physical therapists specified which postoperative analgesia they would prefer if they themselves had TKA or THA surgery (0 [0\%] and 3/18 [16.7\%], respectively) (Table 1). All respondents (19 [100\%]) thought lower extremity nerve blocks increased a patient's risk of falling after surgery. A visual representation of survey responses is provided in Figure 1. The proportion of physical therapists who preferred PNB over other analgesic options for postoperative pain is summarized in Table 1.

\section{Discussion}

To our knowledge, this is the first publication of opinions and preferences of physical therapists with

Table 1. Proportion of physical therapists who preferred nerve block over other* methods

\begin{tabular}{|c|c|c|}
\hline Situation & Fraction $(\%) * *$ & $95 \%$ Confidence Interval $* *$ \\
\hline \multicolumn{3}{|l|}{ When they are treating patients: } \\
\hline Total knee arthroplasty & $1 / 18(5.6)$ & $0.1 \%-27.3 \%$ \\
\hline Total hip arthroplasty & $4 / 18(22.2)$ & $6.4 \%-47.6 \%$ \\
\hline \multicolumn{3}{|l|}{ If they were having surgery: } \\
\hline Knee replacement surgery & $0 / 19(0.0)$ & $0.0 \%-17.7 \%$ \\
\hline Hip replacement surgery & $3 / 18(16.7)$ & $3.6 \%-41.4 \%$ \\
\hline Shoulder replacement surgery & $10 / 19(52.6)$ & $28.9 \%-75.6 \%$ \\
\hline
\end{tabular}




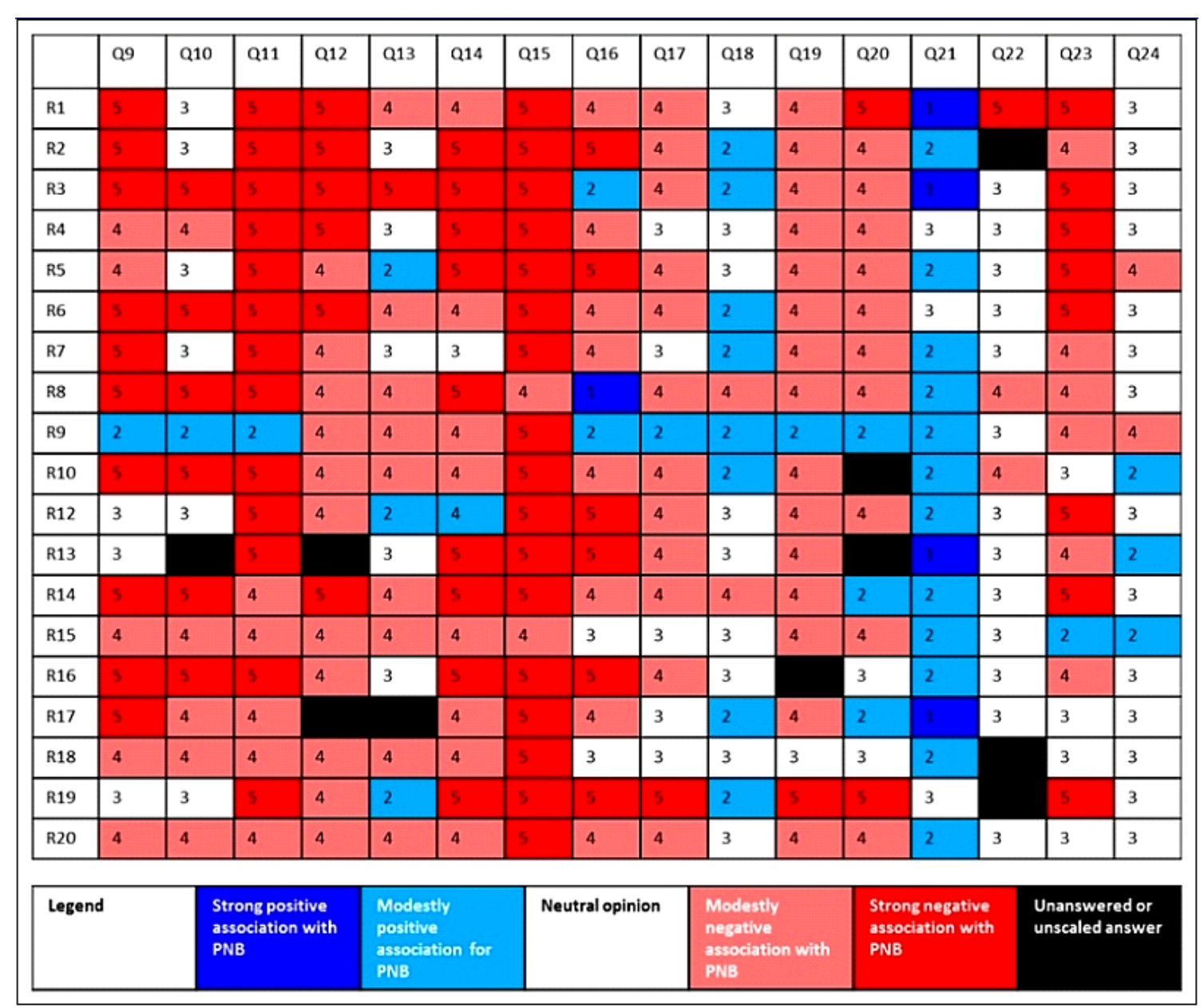

Fig. 1. Color Coded "Info-Graphic" of Scalded Likert-type Questions. Respondent 11 indicated that they had never treated patients after total joint surgery and did not complete the survey. PNB indicates peripheral nerve block; Q, question; R, respondent

regard to use of regional anesthesia after TJR surgery. Based on our results, physical therapists at our institution believe nerve blocks impede patient recovery and increase the risk of falls, independent of their beneficial effects on analgesia. When considering surgery for themselves, the majority of physical therapists indicated they would not want a nerve block. This is a curious finding in the face of evidence that PNBs provide excellent analgesia, facilitate PT, and improve recovery, while not increasing the risk of falls [9, 13-17]. For example, Hebl et al. [17] reported that lower extremity TJR patients who had PNB experienced a shorter hospital length of stay and a reduction in urinary retention and ileus.

The risk of falling associated with PNB is a controversial topic. In a 2013 systematic review and metaanalysis, Johnson et al. [18] found an increased risk of postoperative falls in patients undergoing lower extremity orthopedic surgery receiving continuous lumbar plexus block compared to those not receiving block or only receiving a single-injection nerve block. However, their study had several limitations. First, the frequency of falls in orthopedic patients undergoing continuous PNB was similar to another observed group of surgical patients not receiving nerve blocks. Second, a letter to the editor included in their analysis did not evaluate fall frequency as an end point. Lastly, they did not normalize the data for pre-, peri-, and postoperative factors that might have influenced the risk of fall (e.g., advanced age, comorbid status, ambulation without supervision).

Ilfeld et al. [19] analyzed pooled data from 3 previously published, randomized, triple-blinded, placebocontrolled studies of continuous femoral nerve block after TKA and THA, finding a causal relationship between continuous femoral nerve block and the risk of fall. Again, there were significant limitations to their findings. Of the 6 patients reported to have fallen, 3 did so while ambulating unsupervised, and 1 fell while walking a $\operatorname{dog} 4$ days after TKA. The authors stated the falls occurred in the absence of any muscle weakness. This is perhaps the most important finding in the paper because the argument against the use of regional anesthesia in relation to fall risk is that a nerve block 
produces excessive muscle weakness responsible for gait instability [19].

A recent publication by Memtsoudis et al. [14] retrospectively analyzed data from more than 191,000 patients who underwent TKA. Patients who had falls tended to be older with more comorbidities and were associated with more major complications. Use of neuraxial anesthesia had lower adjusted odds of fall compared with the use of general anesthesia alone, and the use of a PNB was not significantly associated with falls. The authors concluded that no association was found between PNB and inpatient falls [14].

The morbidity, mortality, and economic impact associated with chronic opioid use, both prescription and nonprescription, in the United States has reached epidemic proportions in recent years. Surgery is a welldocumented risk factor for development of chronic opioid dependence [20-22], especially in TKA and THA patients [23]. Providers are obligated to make a strong and concerted effort to use alternative and adjunctive methods to control postoperative pain whenever possible. Regional anesthesia techniques have long been shown to reduce the amount of opioids patients would otherwise require to control perioperatively pain [24-26]. This has been used as an argument to perform nerve blocks in TJR patients. However, newly published data has called into question this previously held axiom that performance of PNB reduces chronic opioid use after surgery. Sun et al. [27] retrospectively analyzed health care utilization data from more than 120,000 TKA patients over a 10 -year period, concluding that, although the use of PNB for TKA may improve short-term outcomes, PNBs do not appear to decrease the risk of persistent opioid use. Notwithstanding, adverse events from opioid-based analgesia, such as severe nausea and vomiting, postoperative ileus, respiratory depression, and delirium, can negatively impact patient satisfaction, hospital length of stay, and morbidity [28].

In our study, we discovered that some physical therapists' preferences appeared to come from perceived benefits of periarticular infiltration over PNBs. For example, with regard to [Q14] (Appendix 2), 95\% of our physical therapists think periarticular infiltration is somewhat or greatly superior to nerve block for THA. No patients at our institution received periarticular infiltration for THA during this time period, so there does not appear to be an experiential basis for this overwhelming perception.

We suspect the basis for the survey data we collected is a presumed muscle weakness following PNB in patients who require PT. What is missing here is a blinded comparison of patients undergoing general surgery with no PNBs or patients undergoing lower extremity surgery without PNBs or even with sham blocks. We do not have these data to present. However, it appears a majority of physical therapists at our institution believe nerve blocks impede patient recovery and increase risk of falls without providing any clinically relevant improvement in analgesia over periarticular infiltration techniques.

This apparent disconnect presents an opportunity for anesthesiologists to educate physical therapists on the data referenced above. It also presents an opportunity to open a dialogue, as physical therapists may have relevant data that is siloed in the PT literature that may not reach anesthesiologists. The needs of the patient outweigh the preferences of both physical therapists and anesthesiologists.

\section{Study Limitations}

Our study is based on anonymous survey data at one institution. It is possible the respondents did not understand the questions as written or the answer choices provided. This survey has not been validated or used previously. The survey responses reflect opinion only and are not meant to imply causal relationships between PNB and PT. The data are derived from one hospital setting, and the opinions of the physical therapists at our institution may vary widely from other practice settings.

\section{Conclusions}

PT remains a clinically important factor in the recovery of patients following TJR surgery. The opinions of the physical therapist on postoperative analgesia regimens, particularly with regard to use of PNB, may influence assessment of recovery and influence surgeons' opinions as to how patients are recovering. We have found that inpatient physical therapists at our institution believe nerve blocks impede patient recovery and increase risk of fall, analgesia notwithstanding. An opportunity exists to un-silo relevant data on these issues for all parties involved in management of patients who have undergone TJR.

\section{Conflict of interest}

Nothing to declare

\section{Funding statement}

No funding was received in support of this study.

\section{References}

1. Minns Lowe CJ, Barker KL, Dewey M, Sackley CM. Effectiveness of physiotherapy exercise after knee arthroplasty for osteoarthritis: systematic review and meta-analysis of randomised controlled trials. BMJ 2007; 335: 812. doi: 10.1136/bmj.39311. 460093.BE

2. Minns Lowe CJ, Barker KL, Dewey ME, Sackley CM. Effectiveness of physiotherapy exercise following hip arthroplasty 
for osteoarthritis: a systematic review of clinical trials. BMC Musculoskelet Disord 2009; 10: 98. doi: 10.1186/1471-2474$10-98$

3. Bandholm T, Kehlet H. Physiotherapy exercise after fast-track total hip and knee arthroplasty: time for reconsideration? Arch Phys Med Rehabil 2012; 93: 1292-1294. doi: 10.1016/ j.apmr.2012.02.014

4. den Hertog A, Gliesche K, Timm J, Mühlbauer B, Zebrowski S. Pathway-controlled fast-track rehabilitation after total knee arthroplasty: a randomized prospective clinical study evaluating the recovery pattern, drug consumption, and length of stay. Arch Orthop Trauma Surg 2012; 132: 1153-1163. doi: 10.1007/ s00402-012-1528-1

5. Raphael M, Jaeger M, van Vlymen J. Easily adoptable total joint arthroplasty program allows discharge home in two days. Can J Anaesth 2011; 58: 902-910. doi: 10.1007/s12630-011-95658

6. Malviya A, Martin K, Harper I, Muller SD, Emmerson KP, Partington PF, et al. Enhanced recovery program for hip and knee replacement reduces death rate. Acta Orthop 2011; 82: 577-581. doi: 10.3109/17453674.2011.618911

7. Dwyer AJ, Tarassoli P, Thomas W, Porter P. Enhanced recovery program in total hip arthroplasty. Indian J Orthop 2012; 46: 407-412. doi: 10.4103/0019-5413.98829

8. Smith TO, McCabe C, Lister S, Christie SP, Cross J. Rehabilitation implications during the development of the Norwich Enhanced Recovery Programme (NERP) for patients following total knee and total hip arthroplasty. Orthop Traumatol Surg Res 2012; 98: 499-505. doi: 10.1016/j.otsr.2012.03.005

9. Xu J, Chen XM, Ma CK, Wang XR. Peripheral nerve blocks for postoperative pain after major knee surgery. Cochrane Database Syst Rev 2014; (12): CD010937. doi: 10.1002/14651858. CD010937

10. Charous MT, Madison SJ, Suresh PJ, Sandhu NS, Loland VJ, Mariano ER, et al. Continuous femoral nerve blocks: varying local anesthetic delivery method (bolus versus basal) to minimize quadriceps motor block while maintaining sensory block. Anesthesiology 2011; 115: 774-781. doi: 10.1097/ALN.0b013 e3182124de 6

11. Wang C, Cai XZ, Yan SG. Comparison of Periarticular Multimodal Drug Injection and Femoral Nerve Block for Postoperative Pain Management in Total Knee Arthroplasty: A Systematic Review and Meta-Analysis. J Arthroplasty 2015; 30: 1281-1286. doi: 10.1016/j.arth.2015.02.005

12. Newcombe RG. Two-sided confidence intervals for the single proportion: comparison of seven methods. Stat Med 1998; 17 : $857-872$

13. Suárez A, Macadar $\mathrm{O}$. The effect of general and spinal anesthesia on balance control in elderly patients. Int Tinnitus J 2008; 14 : 146-151

14. Memtsoudis SG, Danninger T, Rasul R, Poeran J, Gerner P, Stundner $\mathrm{O}$, et al. Inpatient falls after total knee arthroplasty: the role of anesthesia type and peripheral nerve blocks. Anesthesiology 2014; 120: 551-563. doi: 10.1097/ALN. 0000000000000120

15. Ullah H, Samad K, Khan FA. Continuous interscalene brachial plexus block versus parenteral analgesia for postoperative pain relief after major shoulder surgery. Cochrane Database Syst Rev 2014; (2): CD007080. doi: 10.1002/14651858.CD007080.pub2
16. Nader A, Kendall MC, Wixson RL, Chung B, Polakow LM, McCarthy RJ. A randomized trial of epidural analgesia followed by continuous femoral analgesia compared with oral opioid analgesia on short- and long-term functional recovery after total knee replacement. Pain Med 2012; 13: 937-947. doi: 10.1111/j.1526-4637.2012.01409.x

17. Hebl JR, Dilger JA, Byer DE, Kopp SL, Stevens SR, Pagnano $\mathrm{MW}$, et al. A pre-emptive multimodal pathway featuring peripheral nerve block improves perioperative outcomes after major orthopedic surgery. Reg Anesth Pain Med 2008; 33: 510-517. doi: $10.1016 /$ j.rapm.2008.04.008

18. Johnson RL, Kopp SL, Hebl JR, Erwin PJ, Mantilla CB. Falls and major orthopaedic surgery with peripheral nerve blockade: a systematic review and meta-analysis. Br J Anaesth 2013; 110 : 518-528. doi: 10.1093/bja/aet013

19. Ilfeld BM, Duke KB, Donohue MC. The association between lower extremity continuous peripheral nerve blocks and patient falls after knee and hip arthroplasty. Anesth Analg 2010; 111 : 1552-1554. doi: 10.1213/ANE.0b013e3181fb9507

20. Alam A, Gomes T, Zheng H, Mamdani MM, Juurlink DN, Bell CM. Long-term analgesic use after low-risk surgery: a retrospective cohort study. Arch Intern Med 2012; 172: 425430. doi: 10.1001/archinternmed.2011.1827

21. Clarke H, Soneji N, Ko DT, Yun L, Wijeysundera DN. Rates and risk factors for prolonged opioid use after major surgery: population based cohort study. BMJ 2014; 348: g1251. doi: $10.1136 /$ bmj.g 1251

22. Raebel MA, Newcomer SR, Reifler LM, Boudreau D, Elliott TE, DeBar L, et al. Chronic use of opioid medications before and after bariatric surgery. JAMA 2013; 310: 1369-1376. doi: 10.1001/jama.2013.278344

23. Sun EC, Darnall BD, Baker LC, Mackey S. Incidence of and Risk Factors for Chronic Opioid Use Among Opioid-Naive Patients in the Postoperative Period. JAMA Intern Med 2016; 176: 1286-1293. doi: 10.1001/jamainternmed.2016.3298

24. Chan EY, Fransen M, Parker DA, Assam PN, Chua N. Femoral nerve blocks for acute postoperative pain after knee replacement surgery. Cochrane Database Syst Rev 2014; (5): CD009941. doi: 10.1002/14651858.CD009941.pub2

25. Richman JM, Liu SS, Courpas G, Wong R, Rowlingson AJ, McGready J, et al. Does continuous peripheral nerve block provide superior pain control to opioids? A meta-analysis. Anesth Analg 2006; 102: 248-257. doi: 10.1213/01.ANE. $0000181289.09675 .7 \mathrm{D}$

26. Memtsoudis SG, Poeran J, Cozowicz C, Zubizarreta N, Ozbek U, Mazumdar M. The impact of peripheral nerve blocks on perioperative outcome in hip and knee arthroplasty-a populationbased study. Pain 2016; 157: 2341-2349. doi: 10.1097/ j.pain.0000000000000654

27. Sun EC, Bateman BT, Memtsoudis SG, Neuman MD, Mariano ER, Baker LC. Lack of Association Between the Use of Nerve Blockade and the Risk of Postoperative Chronic Opioid Use Among Patients Undergoing Total Knee Arthroplasty: Evidence from the Marketscan Database. Anesth Analg 2017. doi: 10.1213/ANE.0000000000001943. [Epub ahead of print]

28. Wheeler M, Oderda GM, Ashburn MA, Lipman AG. Adverse events associated with postoperative opioid analgesia: a systematic review. J Pain 2002; 3: 159-180. doi: 10.1054/ jpai.2002.123652 


\section{APPENDICES}

\section{Appendix 1}

Survey Questionnaire: Influence of Nerve Blocks on Postoperative Physical Therapy (used with permission of Mayo Foundation for Medical Education and Research, all rights reserved)

How long have you practiced as a physical therapist?

\begin{tabular}{|c|c|c|c|c|c|}
\hline$<1$ year & $1-5$ years & $5-10$ years & $10-15$ years & $15-20$ years & $>20$ years \\
\hline$\square$ & $\square$ & $\square$ & $\square$ & $\square$ & $\square$ \\
\hline
\end{tabular}

How often do you treat total joint replacement surgical patients?

\begin{tabular}{|c|c|c|c|c|}
\hline Never & Rarely & Sometimes & Frequently & Every Day \\
\hline$\square$ & $\square$ & $\square$ & $\square$ & $\square$ \\
\hline
\end{tabular}

When I am treating patients following TOTAL KNEE REPLACEMENT surgery, overall I would prefer that they receive:

\begin{tabular}{|l|r|}
\hline Femoral Nerve Block Only & $\square$ \\
\hline Adductor Canal Block Only & $\square$ \\
\hline Sciatic Nerve Block Only & $\square$ \\
\hline Femoral and Sciatic Nerve Blocks & $\square$ \\
\hline Adductor Canal and Sciatic Nerve Blocks & $\square$ \\
\hline Periarticular Infiltration & $\square$ \\
\hline No Nerve Blocks & $\square$ \\
\hline
\end{tabular}

When I am treating patients following TOTAL HIP REPLACEMENT surgery, overall I would prefer they receive:

\begin{tabular}{|l|l|}
\hline Femoral Nerve Block Only & $\square$ \\
\hline Lumbar Plexus Block Only & $\square$ \\
\hline Sciatic Nerve Block Only & $\square$ \\
\hline Femoral and Sciatic Nerve Blocks & $\square$ \\
\hline Lumbar Plexus and Sciatic Nerve Blocks & $\square$ \\
\hline Periarticular Infiltration & $\square$ \\
\hline No Nerve Blocks & $\square$ \\
\hline
\end{tabular}

If I had a lower extremity joint replacement surgery, I would prefer:

\begin{tabular}{|l|l|}
\hline Spinal Anesthesia & $\square$ \\
\hline General Anesthesia & $\square$ \\
\hline No Preference & $\square$ \\
\hline Other (please specify) & $\square$ \\
\hline
\end{tabular}


If I had a KNEE replacement surgery, I would prefer:

\begin{tabular}{|l|c|}
\hline A Nerve Block & $\square$ \\
\hline Periarticular Infiltration & $\square$ \\
\hline Neither & $\square$ \\
\hline Other (please specify) & \\
\hline
\end{tabular}

If I had a HIP replacement surgery, I would prefer:

\begin{tabular}{|l|c|}
\hline A Nerve Block & $\square$ \\
\hline Periarticular Infiltration & $\square$ \\
\hline Neither & $\square$ \\
\hline Other (please specify) & \\
\hline
\end{tabular}

If I had a SHOULDER replacement surgery, I would prefer:

\begin{tabular}{|l|c|}
\hline A Nerve Block & $\square$ \\
\hline Periarticular Infiltration & $\square$ \\
\hline Neither & $\square$ \\
\hline Other (please specify) & \\
\hline
\end{tabular}

In my opinion, for KNEE replacement surgery, PERIARTICULAR INFILTRATION of local anesthetic is to a nerve block for postoperative PAIN CONTROL.

\begin{tabular}{|c|c|c|c|c|}
\hline Greatly Inferior & Somewhat Inferior & Equivalent & Somewhat Superior & Greatly Superior \\
\hline$\square$ & $\square$ & $\square$ & $\square$ & $\square$ \\
\hline
\end{tabular}

In my opinion, for HIP replacement surgery, PERIARTICULAR INFILTRATION of local anesthetic is to a nerve block for postoperative PAIN CONTROL.

\begin{tabular}{|c|c|c|c|c|}
\hline Greatly Inferior & Somewhat Inferior & Equivalent & Somewhat Superior & Greatly Superior \\
\hline$\square$ & $\square$ & $\square$ & $\square$ & $\square$ \\
\hline
\end{tabular}

In my opinion, for KNEE replacement surgery, PERIARTICULAR INFILTRATION of local anesthetic is to a nerve block for postoperative PHYSICAL THERAPY.

\begin{tabular}{|c|c|c|c|c|}
\hline Greatly Inferior & Somewhat Inferior & Equivalent & Somewhat Superior & Greatly Superior \\
\hline$\square$ & $\square$ & $\square$ & $\square$ & $\square$ \\
\hline
\end{tabular}

In my opinion, for KNEE replacement surgery, adductor canal/saphenous nerve block catheters are compared to a femoral nerve block catheter for postoperative PHYSICAL THERAPY.

\begin{tabular}{|c|c|c|c|c|c|}
\hline Greatly Inferior & $\begin{array}{c}\text { Somewhat } \\
\text { Inferior }\end{array}$ & Equivalent & $\begin{array}{c}\text { Somewhat } \\
\text { Superior }\end{array}$ & Greatly Superior & $\begin{array}{c}\text { I Do Not Have an } \\
\text { Opinion }\end{array}$ \\
\hline$\square$ & $\square$ & $\square$ & $\square$ & $\square$ & $\square$ \\
\hline
\end{tabular}

In my opinion, for KNEE replacement surgery, adductor canal/saphenous nerve block catheters are compared to a femoral nerve block catheter for postoperative PAIN.

\begin{tabular}{|c|c|c|c|c|c|}
\hline Greatly Inferior & $\begin{array}{c}\text { Somewhat } \\
\text { Inferior }\end{array}$ & Equivalent & $\begin{array}{c}\text { Somewhat } \\
\text { Superior }\end{array}$ & Greatly Superior & $\begin{array}{c}\text { I Do Not Have an } \\
\text { Opinion }\end{array}$ \\
\hline$\square$ & $\square$ & $\square$ & $\square$ & $\square$ & $\square$ \\
\hline
\end{tabular}


In my opinion, for HIP replacement surgery, PERIARTICULAR INFILTRATION of local anesthetic is to a nerve block for postoperative PHYSICAL THERAPY.

\begin{tabular}{|c|c|c|c|c|}
\hline Greatly Inferior & Somewhat Inferior & Equivalent & Somewhat Superior & Greatly Superior \\
\hline$\square$ & $\square$ & $\square$ & $\square$ & $\square$ \\
\hline
\end{tabular}

In my opinion, lower extremity nerve blocks the risk of patients falling.

\begin{tabular}{|c|c|c|c|c|}
\hline Strongly Decrease & Somewhat Decrease & $\begin{array}{c}\text { Neither Increase nor } \\
\text { Decrease }\end{array}$ & Somewhat Increase & Strongly Increase \\
\hline$\square$ & $\square$ & $\square$ & $\square$ & $\square$ \\
\hline
\end{tabular}

In my opinion, nerve blocks the patient's ability to participate in physical therapy.

\begin{tabular}{|c|c|c|c|c|}
\hline Strongly Impede & Somewhat Impede & $\begin{array}{c}\text { Neither Impede nor } \\
\text { Facilitate }\end{array}$ & Somewhat Facilitate & Strongly Facilitate \\
\hline$\square$ & $\square$ & $\square$ & $\square$ & $\square$ \\
\hline
\end{tabular}

In my opinion, nerve blocks a patient's recovery after LOWER EXTREMITY (knee and hip) joint replacement surgery.

\begin{tabular}{|c|c|c|c|c|}
\hline Strongly Impede & Somewhat Impede & $\begin{array}{c}\text { Neither Impede nor } \\
\text { Facilitate }\end{array}$ & Somewhat Facilitate & Strongly Facilitate \\
\hline$\square$ & $\square$ & $\square$ & $\square$ & $\square$ \\
\hline
\end{tabular}

In my opinion, nerve blocks a patient's recovery after TOTAL SHOULDER joint replacement surgery.

\begin{tabular}{|c|c|c|c|c|}
\hline Strongly Impede & Somewhat Impede & $\begin{array}{c}\text { Neither Impede nor } \\
\text { Facilitate }\end{array}$ & Somewhat Facilitate & Strongly Facilitate \\
\hline$\square$ & $\square$ & $\square$ & $\square$ & $\square$ \\
\hline
\end{tabular}

In my opinion, nerve blocks make physical therapy for me as a physical therapist.

\begin{tabular}{|c|c|c|c|c|c|}
\hline Very Difficult & $\begin{array}{c}\text { Somewhat } \\
\text { Difficult }\end{array}$ & $\begin{array}{c}\text { Neither Difficult } \\
\text { nor Easy }\end{array}$ & $\begin{array}{c}\text { Somewhat } \\
\text { Easy }\end{array}$ & Very Easy & $\begin{array}{c}\text { It Depends on the Surgery } \\
\text { Type }\end{array}$ \\
\hline$\square$ & $\square$ & $\square$ & $\square$ & $\square$ & $\square$ \\
\hline
\end{tabular}

In my opinion, nerve blocks make physical therapy for the patient.

\begin{tabular}{|c|c|c|c|c|c|}
\hline Very Difficult & $\begin{array}{c}\text { Somewhat } \\
\text { Difficult }\end{array}$ & $\begin{array}{c}\text { Neither Difficult } \\
\text { nor Easy }\end{array}$ & $\begin{array}{c}\text { Somewhat } \\
\text { Easy }\end{array}$ & Very Easy & $\begin{array}{c}\text { It Depends on the Surgery } \\
\text { Type }\end{array}$ \\
\hline$\square$ & $\square$ & $\square$ & $\square$ & $\square$ & $\square$ \\
\hline
\end{tabular}

In my opinion, nerve blocks the patient's pain after joint replacement surgery.

\begin{tabular}{|c|c|c|c|c|}
\hline Greatly Worsen & Somewhat Worsen & $\begin{array}{c}\text { Neither Worsen nor } \\
\text { Improve }\end{array}$ & Somewhat Improve & Greatly Improve \\
\hline$\square$ & $\square$ & $\square$ & $\square$ & $\square$ \\
\hline
\end{tabular}


In my opinion, patients having had spinal anesthesia fall than patients having had general anesthesia.

\begin{tabular}{|c|c|c|c|c|}
\hline Much Less Often & $\begin{array}{c}\text { Somewhat Less } \\
\text { Often }\end{array}$ & $\begin{array}{c}\text { Neither More nor } \\
\text { Less Often }\end{array}$ & $\begin{array}{c}\text { Somewhat More } \\
\text { Often }\end{array}$ & Much More Often \\
\hline$\square$ & $\square$ & $\square$ & $\square$ & $\square$ \\
\hline
\end{tabular}

I feel that routine use of a knee immobilizer after knee replacement surgery would patients receiving a nerve block for postoperative pain relief.

patient safety in

\begin{tabular}{|c|c|c|c|c|}
\hline Strongly Decrease & Somewhat Decrease & $\begin{array}{c}\text { Neither Decrease nor } \\
\text { Increase }\end{array}$ & Somewhat Increase & Strongly Increase \\
\hline$\square$ & $\square$ & $\square$ & $\square$ & $\square$ \\
\hline
\end{tabular}

I feel that routine use of a knee immobilizer after knee replacement surgery would patient safety in patients receiving periarticular infiltration for postoperative pain relief.

\begin{tabular}{|c|c|c|c|c|}
\hline Strongly Decrease & Somewhat Decrease & $\begin{array}{c}\text { Neither Decrease nor } \\
\text { Increase }\end{array}$ & Somewhat Increase & Strongly Increase \\
\hline$\square$ & $\square$ & $\square$ & $\square$ & $\square$ \\
\hline
\end{tabular}




\title{
Appendix 2
}

\author{
Summary of Responses
}

\section{Regarding General Questions:}

[Q1] $\quad 85.0 \%, 17 / 20$ indicated they have practiced as a physical therapist for 10 years or longer, with $(35.0 \%) 7 / 20$ having between 15 and 20 years of practice experience.

[Q2] $52.6 \%, 10 / 19$ indicated they treat patients who have undergone TJR surgery frequently or every day.

[Q3] 94.4\%, 17/18 indicated they prefer that patients receive periarticular infiltration or no block at all for TKA.

[Q4] 77.8\%, 14/18 indicated they prefer that patients receive periarticular infiltration or no block at all for THA.

[Q5] $\quad 63.2 \%, 12 / 19$ would prefer a spinal anesthetic if they themselves had a lower extremity joint replacement surgery.

[Q6] $94.7 \%, 18 / 19$ would prefer periarticular infiltration if they had knee replacement surgery.

[Q7] $\quad 72.2 \%, 13 / 18$ would prefer periarticular infiltration if they had hip replacement surgery.

[Q8] $52.6 \%, 10 / 19$ would prefer a nerve block if they had shoulder replacement surgery.

\section{Regarding Postoperative Pain Control:}

[Q9] 78.9\%,15/19 believe periarticular infiltration is somewhat to greatly superior to a nerve block for knee replacement surgery.

[Q10] 61.1\%,11/18 believe periarticular infiltration is somewhat to greatly superior to a nerve block for hip replacement surgery.

[Q13] 52.6\%, 10/19 believe adductor canal block catheters are somewhat to greatly superior to femoral nerve block catheters for knee replacement surgery.

\section{Regarding Postoperative Physical Therapy:}

[Q11] 94.7\%, 18/19 believe periarticular infiltration is somewhat to greatly superior to a nerve block for knee replacement surgery.

[Q12] 94.4\%, 17/18 believe adductor canal block catheters are somewhat to greatly superior to femoral nerve block catheters for knee replacement surgery.

[Q14] 94.7\%, 18/19 believe periarticular infiltration is somewhat to greatly superior to a nerve block for hip replacement surgery.

[Q15] $100 \%, 19 / 19$ believe lower extremity nerve blocks somewhat to greatly increase the risk of patients falling.

[Q16] 73.7\%, 14/19 believe nerve blocks somewhat to strongly impede that the patient's ability to participate in PT.

[Q17] $68.4 \%, 13 / 19$ believe nerve blocks somewhat to strongly impede recovery after lower extremity joint replacement surgery.

[Q18] 47.4\%,9/19 believe nerve blocks neither impede nor facilitate patients' recovery after shoulder replacement surgery.

[Q19] 84.2\%,16/19 believe nerve blocks make PT somewhat to very difficult for the physical therapist.

[Q20] 63.2\% 12/19 believe nerve blocks make PT somewhat to very difficult for the patient.

[Q21] 78.9\%, 15/19 believe nerve blocks somewhat to greatly improve patients' pain after joint replacement surgery.

[Q22] 81.3\%, 13/16 believe patients fall no more often after spinal anesthesia than after general anesthesia. The other $18.8 \%, 3 / 16$ believe patients fall somewhat to much more often after spinal anesthesia.

[Q23] 73.7\%, 14/19 believe routine use of knee immobilizers would somewhat to strongly improve safety in patients with nerve blocks.

[Q24] 73.7\%, 14/19 believe routine use of knee immobilizers would neither worsen nor improve safety in patients with periarticular infiltration. 